\title{
Calculus Reform, Differential Equations and Engineering
}

\author{
Michael Ruane \\ Electrical \& Computer Engineering, Boston University
}

\begin{abstract}
Through much of the 1990's, the National Science Foundation supported the development of new pedagogical methods, textbooks, and teaching materials, including software, for calculus. This was done in response to concerns from mathematicians, and from scientists and engineers in client disciplines who believed students were not being well prepared for further study with calculus applications. The 'calculus reform' movement has significantly changed the teaching and learning of calculus where it is implemented and has been a constant topic of discussion in the mathematics community. Calculus reform is often unknown among engineering faculty.

Three Boston University mathematics faculty developed a 'reform' differential equations course, textbook, and computer labs, incorporating an unusual degree of engineering applications, modeling and jargon. Their systems approach was later disseminated in workshops to the math community. In those workshops, a common theme from the math professors was 'we don't talk with the engineers--they don't even know that we're teaching differently!'

Calculus reform, including the NSF differential equations project at Boston University, emphasizes using graphical solutions, numerical solutions, and symbolic solutions, as well as writing about mathematics, discovery learning, and team-based learning. This talk will describe these elements and discuss the possibilities for closer collaboration between mathematics and engineering around reform of the curriculum.
\end{abstract}

\section{Introduction}

The early 1980's saw growing discussions in the mathematics community about the role and effectiveness of calculus instruction, particularly in the freshman year. Concerns were diverse. Some argued that discrete mathematics should become the core undergraduate mathematics course. Others felt the calculus sequence had lost sight of essentials under the burden of covering an increasing list of topics demanded by client disciplines and publishers. Changing instructional technology and new appreciation for student learning models seemed to require new curricular approaches. ${ }^{1,2}$

In January, 1986, a Tulane University Conference produced a report "Toward a Lean and Lively Calculus" " which attempted to start a complete redesign of single variable calculus pedagogy and content. Almost immediately a strong case was made for computer-based algebra and plotting tools to help students overcome widespread weaknesses in numerical and symbolic 
manipulation in calculus. The Mathematical Association of America (MAA) quickly created a committee on calculus reform to continue the Tulane Conference initiatives, and the National Science Foundation proposed a major calculus reform initiative. About the same time, the National Research Council started a project 'Mathematical Sciences in the Year 2000' to define a calculus for the new century. By 1988 there were 43 NSF projects (\$7M) underway in calculus reform, from the level of community colleges to major research universities ${ }^{4}$. Most projects had some form of computer algebra system to free students from hand manipulations. In return students were asked to address more complicated, realistic problems, to use graphing tools to develop a geometric understanding of calculus, to reflect upon and write about their mathematical work, to explore mathematical problems until they could create meaning and understanding for themselves and to participate in some forms of team-oriented learning.

Early reform efforts frequently just added computer exercises to existing topics (similar to the current 'add a CD in the back' approach to engineering textbook reform). It became apparent that computer exercises alone were merely a patch on the older system, and that a more extensive restructuring of the curriculum was possible with the new computational tools. In particular, students could learn the concepts of calculus and immediately apply them to complicated real problems with appropriate computational tools. Later they would develop symbolic and manipulative skills.

Reform efforts have not been universally embraced and strong critics have emerged. ${ }^{5,6}$ Charges are made that students are 'cheated' by computer work at the cost of terse mathematical derivations. The continuing national debate on educational reform ${ }^{7,8}$ standards-based education, and Science, Math, Engineering, Technology (SMET) education has invoked calculus reform both as a success story and as a misguided effort. Unfortunately, engineers seem to be absent from these discussions, although our students are the largest client group for calculus.

\section{On-going Calculus Reform Activities}

Calculus reform has not faded away, but it also has not been universally adopted. The most popular calculus reform textbook ${ }^{9}$ has been adopted by over 500 institutions, and has even been used widely for high school AP classes. Developed by a consortium of faculty from 11 colleges and secondary schools, this book has now spawned competitors who offer both traditional and reform elements. Multivariate calculus and differential equations have 'reform' texts.

Evaluations of the reform movement has been on-going with the NSF development grants, but with mixed empirical results ${ }^{10,11}$. NSF is currently funding a Clemson University study (NSF 9912017) on long-term student performance under calculus reform. Earlier studies focused on calculus skills, and did not consider how learning experiences and strategies from reform calculus might improve performance in other areas, e.g. computationally intensive engineering curricula. The Clemson study will look at performance in classes outside calculus.

The MAA provides a forum for continuing development and discussion of calculus reform. MAA's Calculus Reform and the First Two Years (CRAFTY) Committee was involved with the original Tulane Conference, and has continued to offer panels and symposia, especially at the 
annual joint meetings of the American Mathematical Society (AMS), Mathematical Association of America (MAA) Association for Women in Mathematics (AWM) and the National Association of Mathematicians (NAM). The Committee on the Undergraduate Program in Mathematics (CUPM) of the MAA launched a new curriculum initiative in 1999, and is working with CRAFTY to conduct a series of workshops to understand the mathematics needs of students in math intensive disciplines ${ }^{12}$. Called the Curriculum Foundation Workshops, these eleven meetings have generated reports that can help initiate discussions between mathematics departments and their colleagues in engineering, physics, computer science, business, health sciences, statistics, biology, chemistry and math education. Specific documents are available addressing the mathematics needed to support study and practice in Chemical Engineering, Civil Engineering, Electrical Engineering and Mechanical Engineering ${ }^{13}$.

\section{The Boston University Differential Equations Project}

Three mathematics professors at Boston University developed a new text ${ }^{14}$, accompanying software, and a web site in order to 'rethink completely the traditional, sophomore-level differential equations course'. The development effort was supported by NSF, which also supported a series of summer dissemination workshops and workshops at the Mathematics Joint Meetings. They have eliminated most specialized techniques and introduced more topics on formulating and interpreting differential equations. They use qualitative methods and extensive computer tools for visualizing solutions, looking for eigenvalues and eigenvectors, and examining the phase plane solution space. Numeric methods are applied throughout.

The project incorporates modeling and draws examples from many disciplines, including engineering. Often these examples are revisited with new techniques and complexity. A dynamical systems perspective in central to the book, and solution behaviors are examined as model parameters are varied. Linear algebra is introduced as needed. Students are regularly expected to complete 'labs' with extensive numerical experimentation, and to write about their findings. Team-based labs are common.

The dissemination workshops were directed towards mathematics professors, and highlighted the systems approach and computational tools supporting the students' investigations. Ample time was provided to apply the computer tools during the workshops. Additionally, one afternoon of each two-day workshop was devoted to engineering applications of differential equations, using their modeling and computational tools. Electronics laboratory space was coordinated at each workshop to allow the mathematicians to construct RC first and second order systems, measure time constants and physically tweak parameters in their equations. The textbook authors served as the teaching assistants in the electronics lab! All survived the labs, and appreciated more the jargon and context of differential equations for their engineering students.

\section{Opportunities for Collaboration}

Collaboration in the Boston University Differential Equations Project began while the book was being drafted. One of the authors (Blanchard) audited the engineering circuit theory course 
(usually taken by students in the same semester as differential equations) and observed how engineering texts present mathematics, apply jargon, and emphasize modeling and interpretation over solution techniques. This experience colored many of the examples and even the topic development used in the text.

The author was the 'token engineer' for the NSF dissemination workshops, and was able to hear how different schools collaborated between mathematics and engineering or other client disciplines. Most reported little if any regular communication between engineering and math faculty, until a crisis arose. This might be a budget cut, a technology proposal, or simply an outraged engineering professor reporting that the students were not being taught 'correctly'. Usually the engineering professor did not exactly know what was being taught or how, just that the end product was unacceptable. Everyone agreed that this was not productive or collegial. The mathematics faculty were often reluctant to ask for help, especially where there was fear that client disciplines would institute 'just-in-time' math and possibly threaten math teaching jobs.

Some continuing collaboration has resulted. As part of an NSF Combined Research and Curriculum Development grant, engineering faculty at Boston University continue to visit the differential equations course each semester to give an applications lecture, usually on the relation of predator prey systems to laser dynamics. The lecture engages the sophomores with lasers and applications, and then uses the computer tools to vary laser cavity characteristics until the equations give desired transient behavior. The lecture is well received by the students, even those outside engineering. Unfortunately, on most days and topics, there remains little connection between the faculty in math and engineering. It has proven difficult to get faculty in a research I institution to commit the time and effort for continuing collaboration, even when they agree it would improve student learning.

\section{Calculus Reform and ABET Reform}

ABET Criteria 2000 curricular reform started later than calculus reform, and has a much broader mandate. But the two efforts share many goals. Both have been shaped by the changing student population, new instructional technologies, renewed emphasis on modeling, qualitative understanding, applications, writing and team learning. The NSF participated in many of the ABET discussions, especially in defining the national needs for an educated technical workforce.

Calculus reform can be a cautionary tale for ABET efforts. Systematic change has been sought for over 15 years in calculus reform, and there is still not wide agreement as to the effectiveness of the changes. Some are opposing the reform movement, and trying to restore older methods. The relentless pace of change in students preparation, technology, and client needs has initiated new calls for reform of the reforms (e.g. the CUPM foundation workshops). These difficulties arose despite a focus on just the calculus. Engineering, with its broader content, will be more vulnerable to parochial battles within its sub disciplines.

Calculus reform has sought to create curricular overhaul through its investment in entirely new textbooks, pedagogy, and instructional technology. While there are some 'old calculus' texts 
repackaged with a $\mathrm{CD}$ in the dust jacket, the 'reform' calculus has been driven by the Harvard project text and similar NSF-funded innovations. Calculus reform has attempted to change both the 'what' and 'how' of teaching. Engineering has yet to take such a broad leap in its curricular changes.

How should engineering respond to calculus reform and its changes in the mathematics experience of our students? What is the appropriate evolution of our teaching to use these new skills and understandings? For example, how should our engineering texts be adapting to the qualitative and numerical tools the students now possess? Should there be more collaborative, constructive or discovery learning? Or should they continue to leave their calculators and laptops at the classroom door?

\section{Conclusions}

With NSF development support and over a decade of experience, calculus reform has introduced new pedagogy, textbooks, and instructional technology to the undergraduate calculus sequence. Continuing mathematics curricular reform has spread to differential equations and is now incorporating more input from client disciplines, including engineering. This has important implications for engineering education and our ABET reforms. First, engineering, facing its new ABET criteria, can learn from the experiences of the mathematics community. Second, as calculus reform changes the skills and attitudes of engineering undergraduates, engineering faculty need to adjust their own instructional methods. Finally, a well-informed dialogue about reform can lead to closer collaboration with our mathematics colleagues.

\section{Acknowledgments}

The Boston University Differential Equations Project was supported by National Science Foundation grants DUE-9352833 (textbook and other course materials development) and DUE9554718 (dissemination workshops). Discussions with Paul Blanchard and Deborah HughesHallett helped shape the opinions in this paper.

\section{Bibliography}

1. $\quad$ http://forum.swarthmore.edu/mathed/calculus.reform.html Selections from Swarthmore's Internet Mathematics Library related to calculus reform.

2. http://www.mste.uiuc.edu/murphy/Papers/CalcReformPaper.html A literature review and brief history of calculus reform, with emphasis on computer algebra systems.

3. Douglas, R.G. (ed.), "Toward a Lean and Lively Calculus", The Mathematical Association of America, Washington, DC, 1986.

4. Haver, W., (ed.) "Calculus: Catalyzing a National Community for Reform", NSF DUE and MAA Notes, Mathematical Association of America, Washington, DC, 1998.

5. Wilson, R., "A Decade of Teaching Reform Calculus'Has Been a Disaster, Critics Charge", The Chronicle of Higher Education, February 7, 1997, p A12-13. 
6. Wu, H., "The Mathematics Education Reform: Why You Should be Concerned and What You Can Do", The American Mathematical Monthly, 104, (10), December 1997, p 946-954.

7. National Commission on Excellence in Education, "A Nation at Risk: The Imperative for Educational Reform", US Government Printing Office, Washington, DC, 1983.

8. $\quad$ Suter, L. (Ed.) "The Learning Curve: What We Are Discovering about US Science and Mathematics Education", National Science Foundation, NSF96-53, 1996.

9. $\quad$ Hughes-Hallett, D., Gleason, A., et al, Calculus, $2^{\text {nd }}$ Ed, John Wiley, 1997.

10. Leitzel, J. and Tucker, A., (ed.) "Assessing Calculus Reform Efforts" MAA Notes, Mathematical Association of America, Washington, DC, 1994.

11. Roberts, A. (ed.) "Calculus The Dynamics of Change", MAA Notes, Mathematical Association of America, Washington, DC, 1995.

12. Barker, W. "The Curriculum Foundations Project" http://www.maa.org/data/news/cupm.html and http://www.maa.org/data/news/curriculum\%5Ffoundations.html

13. Barker, W. Links to all workshop documents are found at http://academic.bowdoin.edu/math/faculty/barker/dissemination/Curriculum_Foundations

14. Blanchard, P., Devaney, R., and Hall, R., Differential Equations, Brooks/Cole Pub Co., 1998.

15. Boston University Ordinary Differential Equations Project http://math.bu.edu/odes/

\section{Biography}

MICHAEL RUANE is Associate Professor of Electrical \& Computer Engineering at Boston University. He received the B.E.E. from Villanova University in 1969, his S.M.E.E. from MIT in 1973, and the Ph.D. in Systems Engineering from MIT in 1980. He spent two years as a Peace Corps volunteer in Sierra Leone, was a staff member of the MIT Energy Laboratory from 1973 until 1977 and is a registered professional engineer (electrical). He joined Boston University in 1980 and is a member of the Boston University Photonics Center.

Proceedings of the 2001 American Society for Engineering Education Annual Conference \& Exposition Copyright $\odot$ 2001, American Society for Engineering Education 